\title{
Experimental and Finite Element Research of Laterally Loaded Pile
}

\author{
Edwin. A, Satish Pranav. D, Murugan Ganesh
}

\begin{abstract}
Piles have been widely used for supporting axial and lateral loads for a variety of civil engineering structures such as high rise buildings, transmission lines, bridge piers and port structures. In many cases, lateral loads govern the design of piles. Piles are commonly used to support bridge structures, tall buildings, transmission line towers etc. where poor subsoil conditions are encountered. To suit the various types of structures and their loading conditions, piles of different types, shapes and sizes are being used in practice, the safety of these structures mainly depends on the ability of supporting piles to resist large amount of lateral forces. These lateral forces may be due to the action of wind in case of onshore structures and due to combination of wind and wave action in case of offshore structures. In case of coastal structures, there are additional berthing forces.
\end{abstract}

Keywords - lateral loads, lateral forces, subsoil, wind and wave action

\section{INTRODUCTION}

The analysis of pile under lateral loading is complicated by the fact that the soil reaction is dependent on the pile movement; on the other hand it is dependent on the soil response. Thus, the problem is one of soil-structure interaction .Piles are columnar elements in a foundation which have the function of transferring load from the superstructure through weak compressible strata or through water, onto stiffer or more compact and less compressible soils or onto rock .

\section{PROCEDURE}

Weigh $0.1 \mathrm{~g}$, each sieve which is to be used, make sure that each sieve is clean before weighing it. Obtain 200-300 g of oven dry soil as a representative sample from the bag of material or as provided to you weigh the sample to $0.1 \mathrm{~g}$ pass the sample through $4.75 \mathrm{~mm}$ IS sieve to find percent gravel, if any sieve remaining soil through a set of sieve by hand shaking the sieve should be accompanied by lateral and vertical movements together with slighting jolting. Use mechanical shaker, if available, sieving should with slighting jolting. use mechanical shaker, if available, sieving should continue at least for 10 minutes and take care to ensure that sieving is complete. Weigh to $0.1 \mathrm{~g}$ each sieve and the pan with soil. Retained on them. Find by subtraction the weight of soil retained on each sieve by dividing the weight retained on each sieve by the original sample weight. Compute the percentage passing (or percentage finer) by

Revised Manuscript Received on April 12, 2019.

Edwin. A, Civil Engineering Department, SRM Institute of Science and Technology, Kattankulathur, Kancheepuram, T.N, India.

SatishPranav.D, Civil Engineering Department, SRM Institute of Science and Technology, Kattankulathur, Kancheepuram, T.N, India.

Murugan Ganesh, Civil Engineering Department, SRM Institute of Science and Technology, Kattankulathur, Kancheepuram, T.N, India. starting with 100 percent and subtracting the percent retain on each sieve as a cumulative procedure

Table 1 Sieve analysis table

\begin{tabular}{|c|c|c|c|c|}
\hline $\begin{array}{c}\text { IS sieve } \\
\text { designation }\end{array}$ & $\begin{array}{c}\text { Weight } \\
\text { of soil } \\
\text { retained } \\
\text { in 'gm' }\end{array}$ & $\begin{array}{c}\text { Percentage } \\
\text { of soil } \\
\text { retained }\end{array}$ & $\begin{array}{c}\text { Cumulative } \\
\text { percentage } \\
\text { of soil } \\
\text { retained }\end{array}$ & $\begin{array}{c}\text { Percentage } \\
\text { finer }\end{array}$ \\
\hline $4.75 \mathrm{~mm}$ & 0 & 0 & 0 & 100 \\
\hline $2.36 \mathrm{~mm}$ & 0 & 0 & 0 & 100 \\
\hline $1.18 \mathrm{~mm}$ & 111 & 22.2 & 22.2 & 77.8 \\
\hline 600 micron & 130 & 26 & 48.2 & 51.8 \\
\hline 300 micron & 221 & 44.2 & 92.4 & 7.6 \\
\hline 150 micron & 32 & 6.4 & 98.8 & 1.2 \\
\hline 75 micron & 4 & 0.8 & 99.6 & 0.4 \\
\hline Pan & 2 & 0.4 & 100 & 0 \\
\hline
\end{tabular}

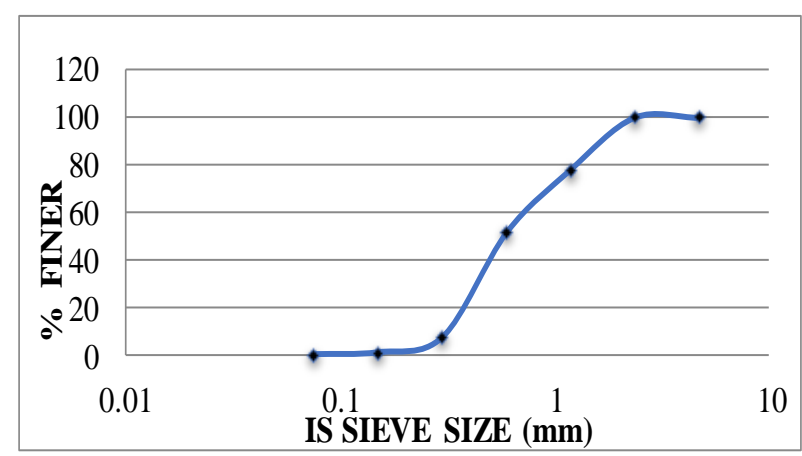

Table 2 Grain size distribution curve

\begin{tabular}{|c|c|c|c|}
\hline S.No & Parameter & Symbol & Values \\
\hline 1 & Gravel & $\%$ & 0 \\
\hline 2 & Coarse sand & $\%$ & 3 \\
\hline 3 & Medium sand & $\%$ & 74 \\
\hline 4 & Fine sand & $\%$ & 22 \\
\hline 5 & Silt and clay & $\%$ & Trace \\
\hline 5 & Effective Size & $\mathrm{D}_{10}$ & 0.25 \\
\hline 6 & Uniformity coefficient & $\mathrm{C}_{\mathrm{u}}$ & 2.08 \\
\hline 7 & $\begin{array}{c}\text { Coefficient of } \\
\text { Curvature }\end{array}$ & $\mathrm{C}_{\mathrm{c}}$ & 1.63 \\
\hline 8 & Specific Gravity & $\mathrm{G}_{\mathrm{s}}$ & 2.63 \\
\hline 9 & Classification & $\mathrm{SP}$ & Poorly graded \\
\hline
\end{tabular}

\section{A. Calculation}

Coefficient of uniformity $\left(\mathrm{C}_{\mathrm{u}}\right)=\mathrm{D}_{60} / \mathrm{D}_{10}$

From graph $\mathrm{D}_{60}=0.74$

$$
\mathrm{D}_{10}=0.33
$$

\section{Published By:}


$\mathrm{C}_{\mathrm{u}}=0.74 / 0.33=2.24$ micron

Co efficient of curvature $\left(C_{c}\right)=D_{30 \wedge 2} /\left(D_{60} D_{10}\right)$

From graph, $\mathrm{D}_{30}=0.47$

Therefore $\mathrm{Cc}=0.47^{2} / 0.74 \times 0.33=0.9045$

$\mathrm{C}_{\mathrm{c}}>1$, it is poorly graded

\subsubsection{SPECIFIC GRAVITY TEST}

Table 3.4 specific gravity table

\begin{tabular}{|l|c|}
\hline Weight of empty pycnometer, $\mathrm{W}_{1}$ & $546 \mathrm{gm}$ \\
\hline Weight of sand + pycnometer, $\mathrm{W}_{2}$ & $946 \mathrm{gm}$ \\
\hline Weight of sand, $\mathrm{W}$ & $400 \mathrm{gm}$ \\
\hline $\begin{array}{l}\text { Weight of sand + pycnometer + water }, \\
\mathrm{W}_{3}\end{array}$ & $1620 \mathrm{gm}$ \\
\hline Weight of pycnometer +full water, $\mathrm{W}_{4}$ & $1372 \mathrm{gm}$ \\
\hline $\begin{array}{l}\text { Weight of equivalent weight of water } \\
\left(\mathrm{W} \omega=\mathrm{W}+\mathrm{W}_{4}-\mathrm{W}_{3}\right) \mathrm{g}\end{array}$ & $152 \mathrm{gm}$ \\
\hline $\begin{array}{l}\text { Specific gravity of soil at } \mathrm{t}^{\circ} \mathrm{C}, \\
\mathrm{G}=\mathrm{W} / \mathrm{W} \omega\end{array}$ & $2.631 \mathrm{gm}$ \\
\hline $\begin{array}{l}\text { Specific gravity of soil at standard } \\
\text { temperature } 27^{\circ} \mathrm{C}, \mathrm{G}\end{array}$ & $2.631 \mathrm{gm}$ \\
\hline
\end{tabular}

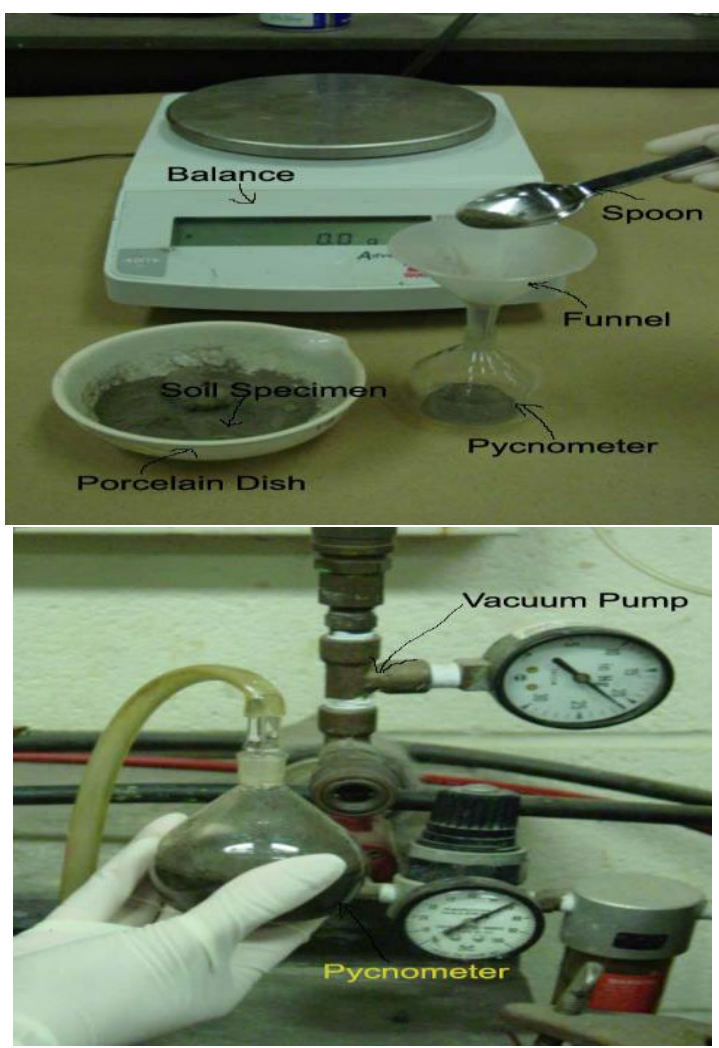

Fig 3.5 Specific gravity test setup

\section{RESULTS AND DISCUSSIONS}

The results of laboratory tests on model piles embedded in dry sand bed of loose density to find the performance of pile due to ground movement are presented and discussed in this chapter. The performance of pile was studied under the following aspects,

- Piles of different L/D ratios

The results obtained from the test on piles of different $\mathrm{L} / \mathrm{D}$ ratios are discussed in the following sequence.

\section{A. Experimental results}

- Pile head deflection of short pile
- Pile head deflection of intermediate pile

- Pile head deflection of long pile

- Relation between $\delta$ max/Lpvs lateral load capacity

B. Numerical results

- Pile head deflection

- Comparision of experimental and numerical results

Pile head deflection of short pile.

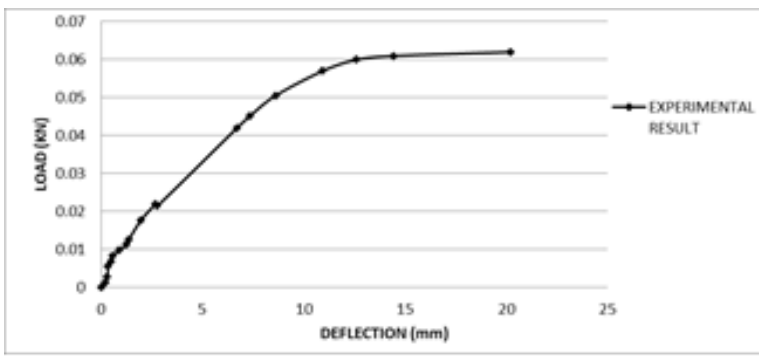

Fig: 3.1Pile head deflection of short pile obtain from experimental result

Fig 3.1 shows the variation of pile head deflection with lateral load for pile of L/D ratio 20 embedded in loose sand. It can be observed that the pile head deflection increases with applied load. For the lateral load more than $60 \mathrm{~N}$, the slope of the pile head deflection curve is changed and rate of increase in deflection of pile head is also decreased on further increase in lateral load. The allowable lateral deflection of the pile is taken as $20 \%$ of the pile diameter (NarasimhaRao et al., 1998) and hence the load corresponding to deflection $2.5 \mathrm{~mm}$, in this case, is taken as the lateral load capacity of the piles. The comparisons for various cases are made for this lateral load corresponding to deflection of the pile. The lateral load capacity is found to be $18 \mathrm{~N}$.

Pile head deflection of intermediate pile.

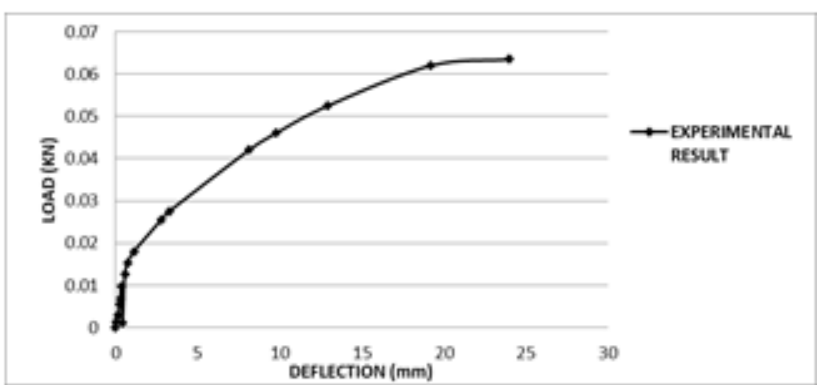

Fig: 3.2 Pile head deflection of intermediate pile obtained from experimental result

Fig 3.2 shows the variation of pile head deflection with lateral load for pile of $\mathrm{L} / \mathrm{D}$ ratio 30 embedded in loose sand. It can be observed that the pile head deflection increases with applied load. For the lateral load more than $62 \mathrm{~N}$, the slope of the pile head deflection curve is changed and rate of increase in deflection of pile head is also decreased on further increase in lateral load. The lateral load capacity of the intermediate pile is observed to be $22 \mathrm{~N}$ which is slightly higher than that of the short pile whose L/D ratio is 20 . Blue Eyes Intelligence Engineering \& Sciences Publication 
Pile head deflection of Long pile.

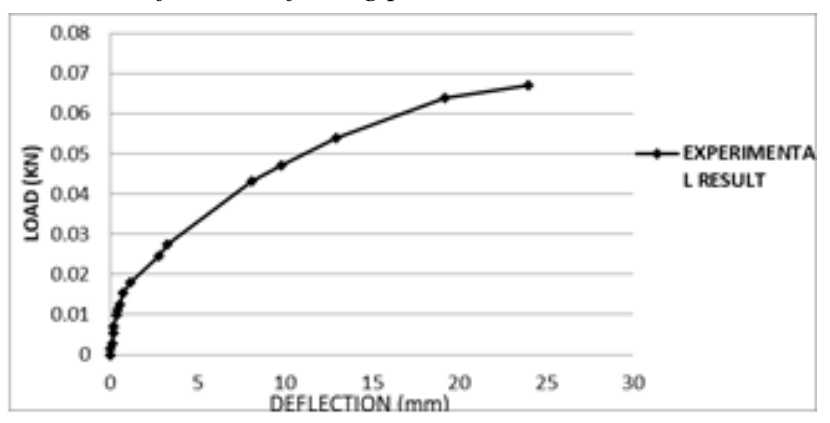

Fig: 3.3 graph of pile head deflection of long pile obtain from experimental result

Fig 3.3 shows the variation of pile head deflection with lateral load for pile of L/D ratio 40 embedded in loose sand. It can be observed that the pile head deflection increases with applied load. For the lateral load more than $62 \mathrm{~N}$, the slope of the pile head deflection curve is changed and rate of increase in deflection of pile head is also decreased on further increase in lateral load. The lateral load capacity of the long pile is observed to be $25 \mathrm{~N}$ which is higher than both short and intermediate pile.

\section{Relation between Deflection/Total length and lateral load}

Fig 3.4 shows the relationship between Deflection/Total length and lateral load for piles of embedded in loose sand bed respectively. The response is reduced almost linear

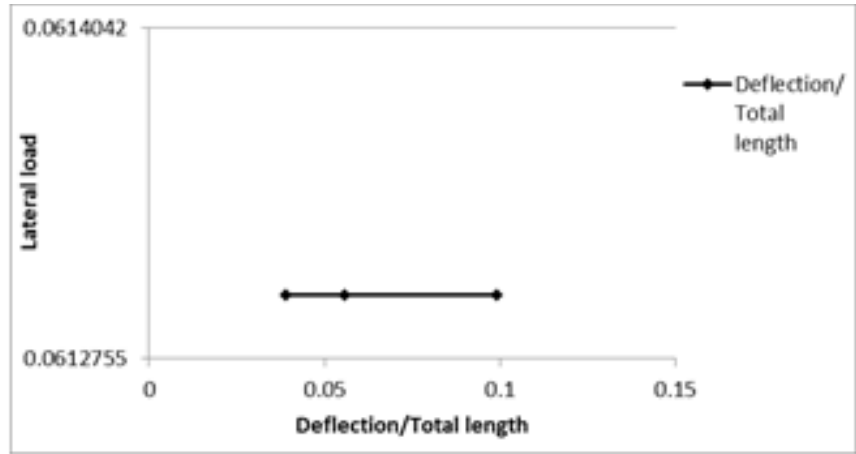

Fig: 3.4 Graph between Deflection/Total length and lateral load

Lateral load capacity of piles of different length

Table 3.1 lateral load capacity of pile of different length

\begin{tabular}{|c|c|}
\hline Length(mm) & Ultimate Lateral Load(N) \\
\hline 230 & 15.24 \\
\hline 340 & 16.25 \\
\hline 460 & 17.52 \\
\hline
\end{tabular}

From the results, it can be seen that lateral load capacity increases with increase in length of the pile. This is because the passive resistance is mobilized on increased embedment of pile, i.e. when the embedment length of pile increases.

\section{INTRODUCTION AND VALIDATION OF PLAXIS}

A case study was used for verification of the finite element model of the whole geotechnical structure. The case study deals with lateral load in which the deflection response of bored piles in cemented sand were examined by field test on single pile under lateral load (Ismail, 1998). All piles were $0.3 \mathrm{~m}$ in diameter and had a length of $3 \mathrm{~m}$ or $5 \mathrm{~m}$. The site of this load test was in Kuwait. The surface soil to depth of $3.5 \mathrm{~m}$ was characterized as having both components of shear strength, both effective parameters. The soil profile consists of a medium dense cemented silty sand layer to a depth $3 \mathrm{~m}$. This is underlain by medium dense to very dense silty sand with cemented lumps to the bottom of the borehole. Ground water was not encountered within the depth of the borehole.

\begin{tabular}{|c|c|c|c|c|}
\hline $\begin{array}{l}\text { Parameter } \\
\text { Unit }\end{array}$ & Name & Soil1 & Soil2 & Pile \\
\hline $\begin{array}{l}\text { Unsaturated } \\
\text { Soil Weight } \\
\text { KN/m³ } \\
\end{array}$ & $\geq_{\text {unsat }}$ & 18 & 19 & 25 \\
\hline $\begin{array}{l}\text { Saturated Soil } \\
\mathrm{KN} / \mathrm{m}^{3}\end{array}$ & $\geq_{\text {sat }}$ & 18 & 19 & - \\
\hline $\begin{array}{l}\text { Young's } \\
\text { Modulus KPa }\end{array}$ & $\mathrm{E}$ & 13000 & 13000 & 2000000000 \\
\hline Poisson ratio & $\mathrm{V}$ & 0.3 & 0.3 & 0.15 \\
\hline $\begin{array}{l}\text { Cohesion } \\
\text { intercept KPa }\end{array}$ & $C^{\prime}$ & 1 & & - \\
\hline Friction angle & $\varphi$ & 45 & & - \\
\hline
\end{tabular}

Table 4.1 Represent the finite element results

Soil 1: Medium dense cemented silty sand layer

Soil 2: Medium dense to very dense silty sand with cemented lumps

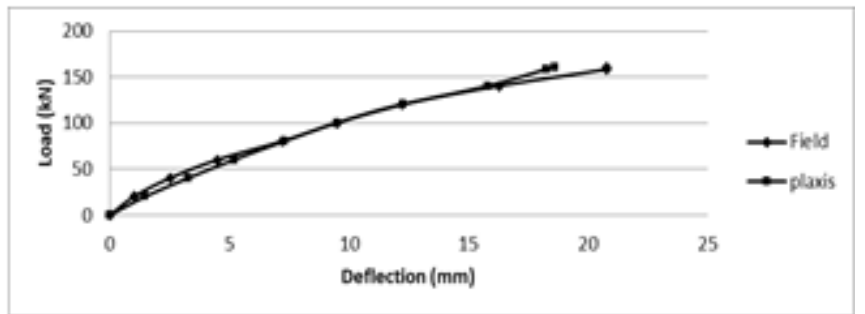

Fig: 4.1 Comparison between the finite element result and field test data

The comparison between the finite element results and field test data is shown in Fig.4.1

Also, the numerical simulation is reasonably accurate for the problem of laterally loaded piles and pile - soil interaction over a wide range of deformation

\section{NUMERICAL ANALYSIS}

\section{A. Generation of Mesh}

Finite element analyses were performed using the software PLAXIS 3D FOUNDATION version 1.1. In the finite element method, a continuum is divided into a number of (volume) elements. Each element consists of a number of nodes. Each node has a number of degrees of freedom that correspond to discrete values of the unknowns in the boundary value problem to be solved. In order to perform the finite element calculations, the geometry has to be

Published By: 
divided into elements. A composition of finite elements is called finite element mesh. The basic soil elements of a 3D finite element mesh are represented by the 15 -node wedge elements. These elements are generated from the 6-node triangular elements. The 15-node wedge element is composed of 6-node triangles in horizontal direction and 8node quadrilaterals in vertical direction. Fig 5.1 and 5.2 shows the $2 \mathrm{D}$ and $3 \mathrm{D}$ mesh generated for the analyses.

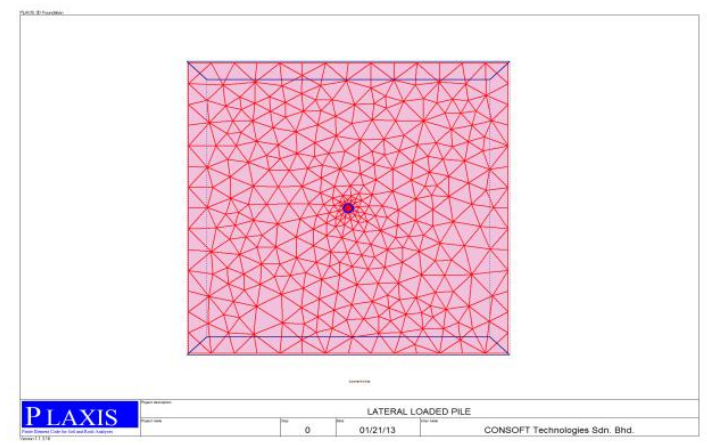

Fig: 5.1 2D Mesh

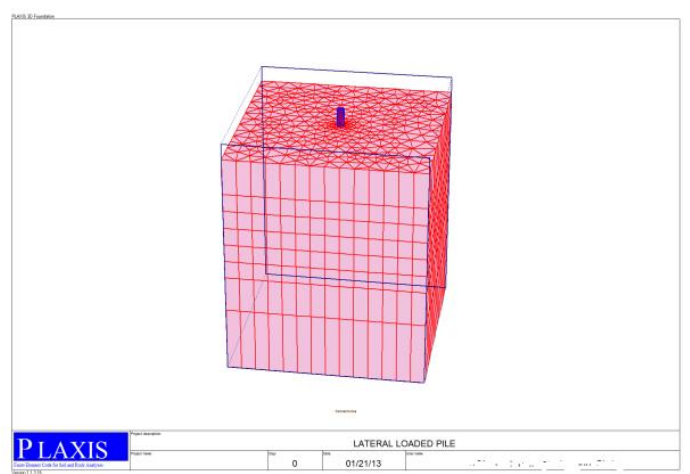

Fig: 5.2 3D Mesh

\section{B. Pile Head Deflections}

Figure 5.3, 5.4 and shows the Deflection vs Lateral Load Profile for $\mathrm{L} / \mathrm{D}=20$ and 30 respectively. The observations shows that, Linear elastic model (perfect-plasticity) used to model the pile and Mohr-Coulomb model used to model the non-linear performance of surrounded soil which involves two main parameters, namely the cohesion intercept, c' and the friction angle, $\varphi$ 'and three additional parameters namely Young's modulus, E', Poisson's ratio, v', and the dilatancy angle, $\psi$ ' needed to calculate the complete $\sigma-\varepsilon$ behavior holds good.

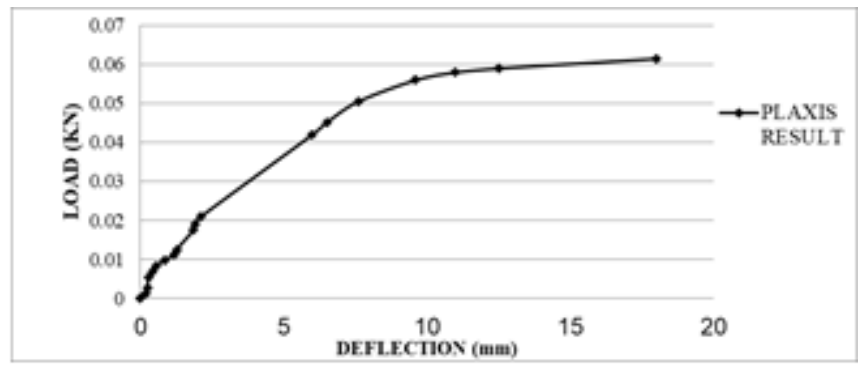

Fig:5.3 Pile head deflection of SHORT pile obtained from Plaxis value

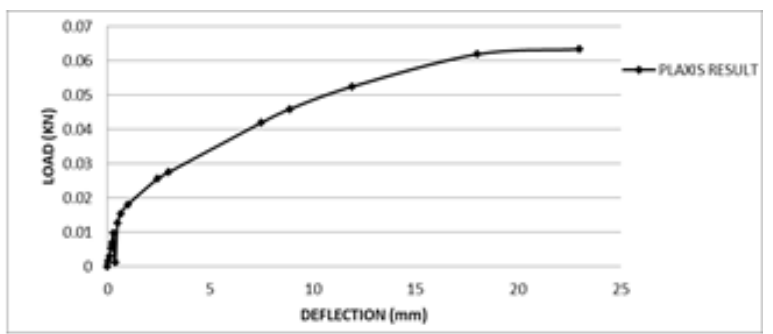

Fig: 5.4 Pile head deflection of INTERMIDIATE pile by using Plaxis result

Fig 5.5 shows the load deflection profile for the pile of $\mathrm{L} / \mathrm{D}$ ratio 40 . The deflection of the long pile increases as the lateral load increases. The deflection starts decreasing after the pile reaches its ultimate resistant value.

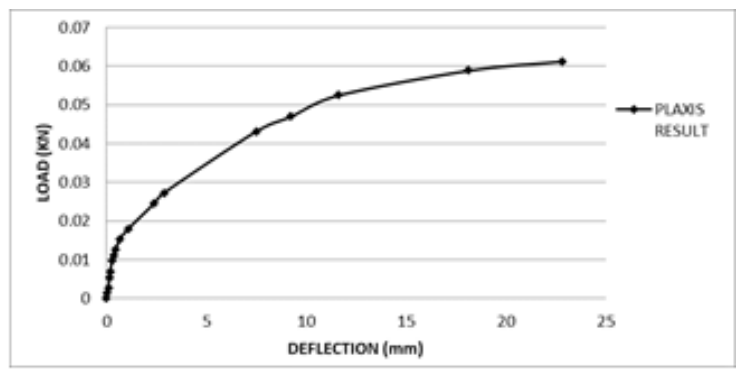

Fig: 5.5 Pile head deflection of LONG pile by using Plaxis result

Fig 5.7 and 5.8 shows the pile head deflection and horizontal displacement of soil respectively. This confirms the behavior of long pile as mentioned by Poulos and Davis.

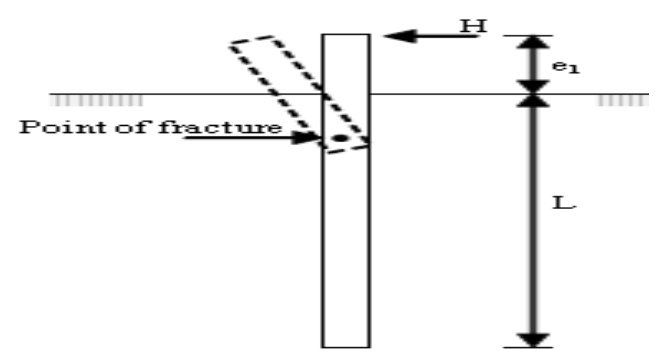

Fig: 5.6 sketch diagram of deflected pile head

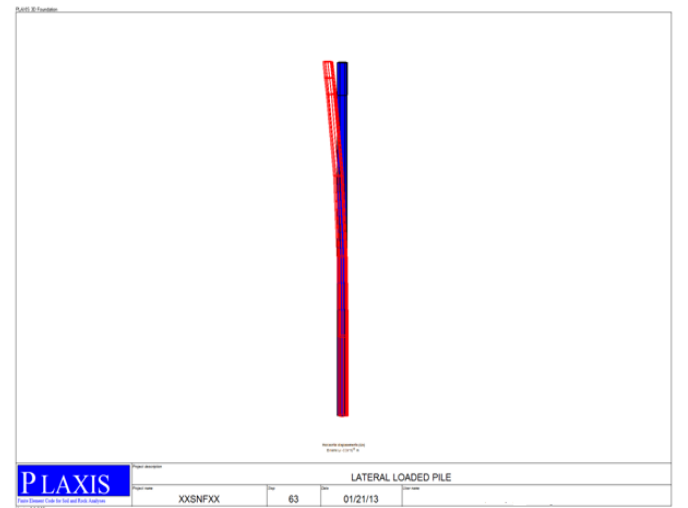

Fig:5.7 Deflection of pile obtained by plaxis-3D foundation 


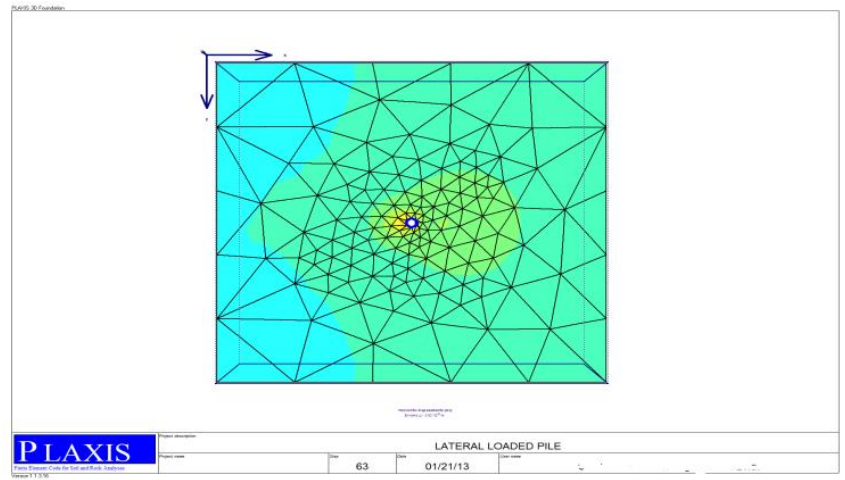

Fig:5.8 lateral loaded pile obtained by Plaxis -3D Foundation

\section{COMPARISON OF EXPERIMENTAL AND NUMERICAL RESULTS}

The experimental results are compared with the finite element analyses Plaxis 3D Foundation. The variation of deflection of pile with lateral load for a pile of $\mathrm{L} / \mathrm{D}=10$ embedded in loose sand are presented in the fig 6.1. The deflection presented in the figure is deflection of pile measured at the head of respective piles. The deflection of piles observed in the Plaxis show the trend as seen in the model tests on single piles. Deflection at the pile head increases with lateral load with increasing rate. However, the slope of the curve is changed it direction for the lateral load of $60 \mathrm{~N}$ in both experimental and numerical results.

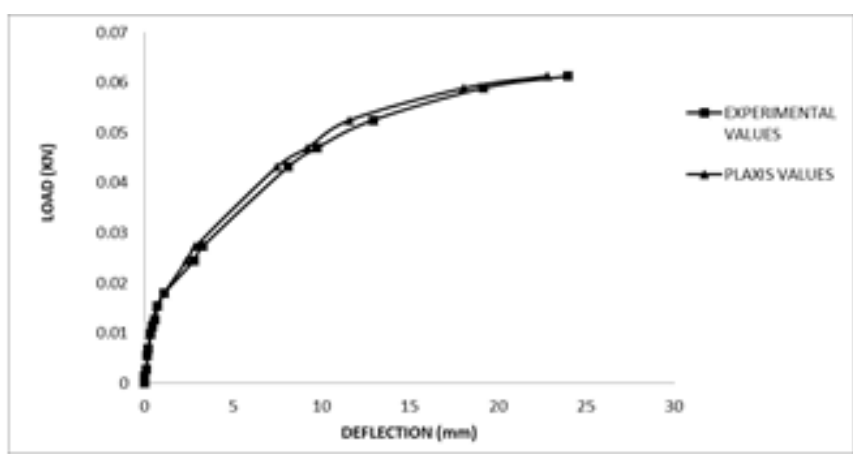

Fig: 6.1 Graph represent the comparison between experimental value and plaxis values for short pile

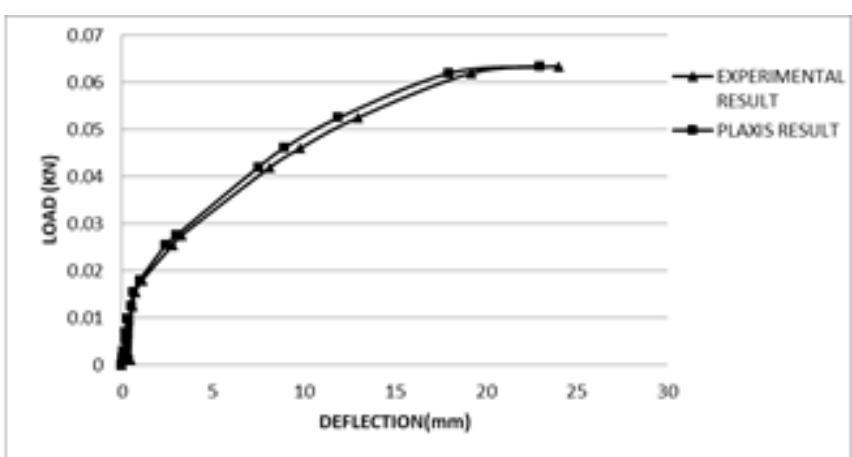

Fig: 6.2 Graph represent the comparison between experimental values and plaxis values for INTERMIDIATE pile

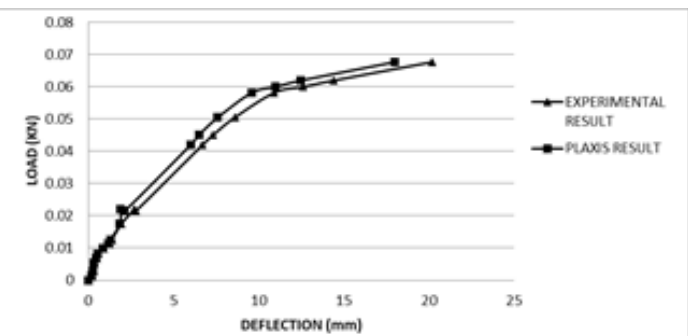

Fig: 6.3 Graph represents the comparison value for experimental result and plaxis result for LONG pile.

Figs 6.2 and 6.3 show the comparisons of deflection vs lateral load for the $L / D=30$ and $L / D=40$ respectively. The finite element analysis slightlyunderestimates the deflection when compared with experimental results in case of pile groups.

\section{CONCLUSION}

An attempt was made in this research to study the behavior of pile subjected to lateral load. Piles of three L/D ratios such as 20, 30 and 40 were chosen for the study. The tests were carried out on sand beds of density via loose $\left(\gamma=15.3 \mathrm{kN} / \mathrm{m}^{3}\right)$. The following are the important conclusions derived from the tests conducted on piles.

- The pile head deflection for longer piles is more in case of loose sand when compared with intermediate and long piles.

- On comparing the behavior of piles, the percentage increase in maximum deflection is $3.3 \%$ for $\mathrm{L} / \mathrm{D}$ of 30 and $13.3 \%$ for $\mathrm{L} / \mathrm{D}$ of 40 in loose sand.

- The pile head deflection is found to increase exponentially with increasing lateral load.

- The lateral load capacity of short pile is observed to be $15.24 \mathrm{~N}$ and intermediate and long pile is $16.25 \mathrm{~N}$ and $17.52 \mathrm{~N}$ respectively.

- The lateral load capacity of longer pile is higher than shorter pile due to the passive resistance is mobilized on increased embedment of pile.

- The influence of on the lateral response of piles installed in sand is also analyzed through 3dimensional finite element analyses and its compares reasonably with experimental results.

\section{APPENDIX}

It is optional. Appendixes, if needed, appear before the acknowledgment.

\section{ACKNOWLEDGMENT}

It is optional. The preferred spelling of the word "acknowledgment" in American English is without an "e" after the "g." Use the singular heading even if you have many acknowledgments. Avoid expressions such as "One of us (S.B.A.) would like to thank ... ." Instead, write "F. A. Author thanks "Sponsor and financial support acknowledgments are placed in the unnumbered footnote on the first page.

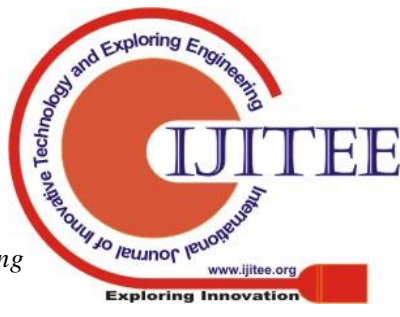




\section{Experimental And Finite Element Research Of Laterally Loaded Pile}

\section{REFERENCES}

1. Anderson. "Lateral load test on piles or drilled shafts under lateral load" (2003), European journal of geotechnical engineering.

2. Ashish Mehta. "Behaviour of laterally loaded piles" (2010), International journal of science and technology vol.2 (12), $2010,7252-7254$.

3. Basack "Simplified theoretical analyzes of response of a single pile embedded in cohesion less medium under lateral load" (2004)., International journal of science and technology.

4. BehrouzGatmiri . "A numerical modeling of pile groups under lateral loading in sand" (2011) Pan-Am CGS, Geotechnical conference.

5. Broms "Ultimate lateral resistance and lateral deflection for short rigid pile and long elastic pile" (1964).

6. Charles . "Lateral load test of one single pile and three pile groups" in Hong Kong (2001).

7. C.Y Lee "Estimating laterally loaded pile response" (2006),numerical and analytical methods in geomechanics.

8. Davisson and Gill "The behavior of laterally loaded pile in a two layer system analytically” (1963) ,American journal Engineering .

9. DipanjanBasu "Analysis of laterally loaded piles in a multilayered soil deposit" .(2008), publication FHWA /IN/JTRP2007/23, Joint transportation research program

10. Ke Yang "Analysis laterally loaded drilled shafts in rock" (2006), Canadian geotechnical journal .

11. MallikarjunaRao . "Ultimate lateral load capacity and ground line deflection of rigid piles in clays" (1999), European journal of geotechnical engineering .

12. Matlock and Reese "laterally loaded pile problem of beam on elastic foundation" (1960), Sciencedirect .

13. P.J. Ananthanathan . "Experimental and theoretical behaviour of laterally loaded piles" (2009), American journal of geotechnical engineering .

14. P.K. Basudhar . "This paper pertains to the development of a theoretical analysis of a laterally loaded pile using $p-y$ diagram to predict the flexural behavior of a pile" (2009), IGC, Guntur, India .

15. RongqingLi . "Analysisoflatellary loaded pile in layered soils" (2008), European Journal of geotechnical engineering ,vol, 3 .

16. Salini. U . "The behaviour of pile under lateral load is studied through laboratory experiments on model mild steel and aluminum pipe piles driven into dry river sand" (2009), European journal of geotechnical engineering, vol . 14.

17. Vishwas A. Sawant . "Finite element analysis for laterally loaded piles in sloping ground" (2012), Coupled System mechanics, vol. 1 , no. 1 (2012), 59-78 .

18. William Higgins . "The Fourier finite element analysis of laterally loaded pile" (2011) .

19. ZakiaKhelifi. "Moleding the behavior of axially and laterally loaded pile with a contact model" (2011), European journal of geotechnical engineering, vol. 16 (2011).

20. Zamri H. Chik . "Lateral behavior of single pile in cohessionless soil subjected to both vertical and horizontal load" (2009) , European journal of scientific research, ISSN 1450-216X, vol. 29, no.2 (2009), pp-194-205 .

\section{AUTHORS PROFILE}

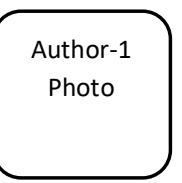

Author-2

Photo
First Author personal profile which contains their education details, their publications, research work, membership, achievements, with photo that will be maximum 200-400 words.

Second Author personal profile which contains their education details, their publications, research work, membership, achievements, with photo that will be maximum 200-400 words.
Third Author personal profile which contains their education details,

Author-3 their publications, research work, membership,
achievements, with photo that will be maximum 200-400

Photo 